\title{
Modern Orthosis Therapy for Scoliosis, Kyphosis and other postural defects. Report by Dr. David Rosenberg, M.D. of Georgia and colleagues.
}

Dr. Carolina Diamandis ${ }^{1}$, Adrian Tudor ${ }^{1}$, and David Rosenberg ${ }^{1}$

${ }^{1}$ Affiliation not available

October 18, 2021

\begin{abstract}
As a conservative form of treatment for scoliosis and kyphosis (postural deficits), orthotic therapy still represents the gold standard of non-surgical orthopedics. In light of increasingly frequent complications due to dangerous wound infections caused by multi-resistant germs, it is to be expected that the treatment of clinically relevant postural deformities will again be increasingly conservative in the future. Apart from "saving" the patient from wearing an orthosis, surgical (invasive) treatment has not been proven to be superior.
\end{abstract}

\section{Hosted file}

Orthosis therapy for postural defects.pdf available at https://authorea.com/users/410930/ articles/542073-modern-orthosis-therapy-for-scoliosis-kyphosis-and-other-posturaldefects-report-by-dr-david-rosenberg-m-d-of-georgia-and-colleagues 